\title{
Minimally invasive enteroscopically guided small bowel resection
}

\author{
Tommy CH Man *, KC Ng, KW Wong, Francis PT Mok
}

\section{A B S T R A C T}

Localisation of small bowel pathology is often difficult, especially intramural small bowel lesions. Even with the use of laparoscopy, visualisation of small bowel lesion is not always possible. The most accurate method to identify such a lesion is by laparotomy with direct visualisation and palpation of the lesion. However, the recent trend in surgical development aims for minimally invasive procedures while keeping the excision of surgical pathology safe and complete, with less surgical trauma. This report illustrates a case of minimally invasive enteroscopically guided small bowel resection.

\section{Hong Kong Med J 2015;21:280-2}

DOI: $10.12809 / \mathrm{hkmj} 144270$

TCH Man *, MB, BS

$\mathrm{KC} \mathrm{Ng}, \mathrm{MB}, \mathrm{BS}$

KW Wong, $M B, B S$

FPT Mok, MB, BS

Department of Surgery, Caritas Medical Centre, Shamshuipo, Hong Kong

* Corresponding author: manchunhin@gmail.com

\section{Case report}

A 64-year-old male with a history of hepatic carcinosarcoma had his right hemihepatectomy done in 2011. The resection margins were clear and interval computed tomography (CT) scans did not reveal any recurrence.

One year after the surgery he was admitted for complaints of non-specific abdominal pain, melena, and dizziness. On admission, the haemoglobin level was only $50 \mathrm{~g} / \mathrm{L}$ although his oesophagogastroduodenoscopy and colonoscopy were normal. Capsule endoscopy was performed and this showed a fungating tumour in the jejunum with evidence of bleeding. Another CT scan was arranged which confirmed that there was a $2.5-\mathrm{cm}$ intraluminal lesion in the small bowel, suggesting a probable occurrence of gastro-intestinal stromal tumour.

Subsequently, single-port laparoscopic resection of the small bowel tumour under singleballoon enteroscopic guidance was performed. The patient was operated on under general anaesthesia in supine position with prophylactic antibiotics. The single-balloon enteroscope (Olympus SIFQ260; Olympus Medical Systems Corp, Japan) was used to locate the site of tumour (Fig 1a). The lesion was marked with endomarker (Fig 1b) and lipiodol injection, and the enteroscope was left in situ in order to guide the site of skin incision. Fluoroscopy and transillumination of the small bowel at the site

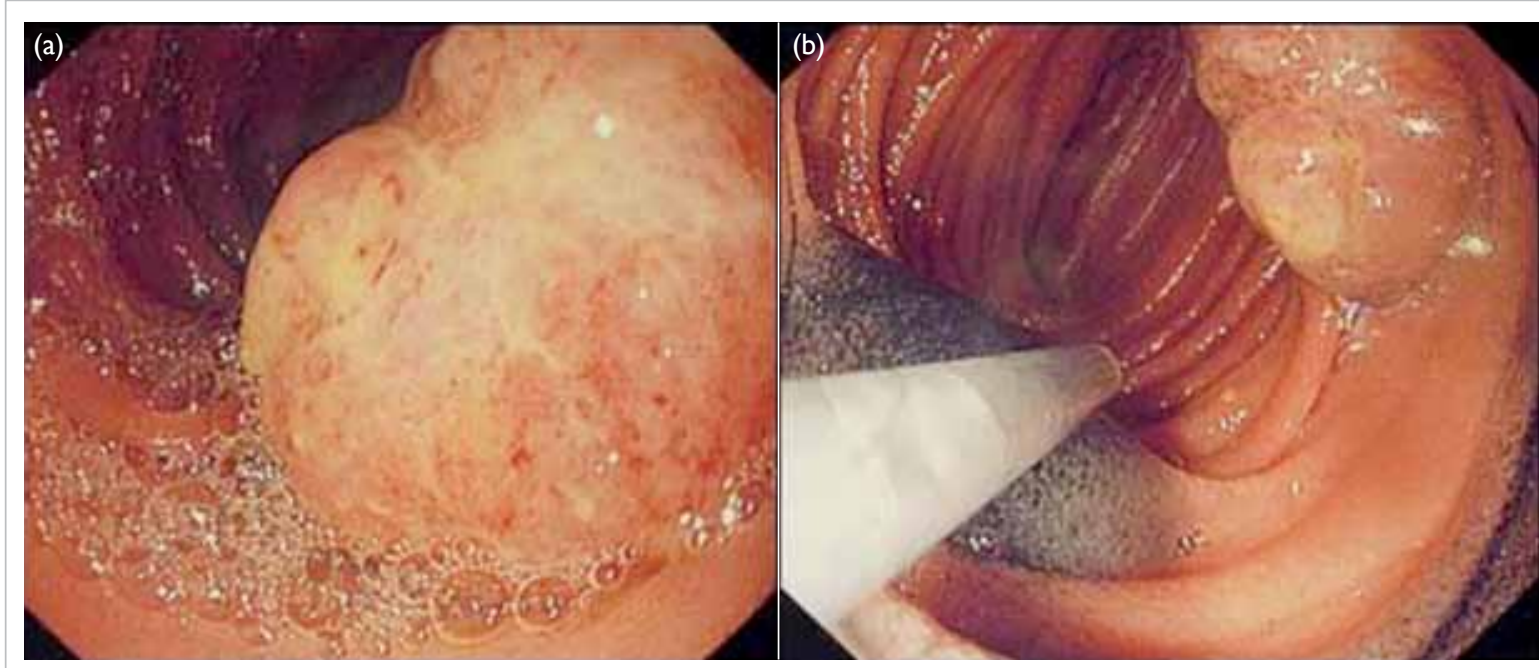

FIG I. Tumour at proximal jejunum (a) before and (b) after endomarker injection 
of lesion confirmed that the tumour was situated in the left upper quadrant of the abdomen (Figs $2 \mathrm{a}$ and 2b).

A 2-cm incision was made for laparoscopic procedure using a Hassan laparoscopic port that was inserted with an 8-degree laparoscope with working channel (OLYMPUS A5252A laparoscope; Olympus Medical Systems Corp, Germany). Laparoscopy procedure confirmed that there were no suspicious hepatic and peritoneal nodules. The diseased part of the small bowel was taken out using a grasper through the working channel after extension of the skin wound (Fig 2c). Usual small bowel resection was done with primary anastomosis using linear staplers and the entire procedure lasted for about 225 minutes.

The patient tolerated the whole procedure well and his recovery was satisfactory. He gradually resumed oral feeding and was fit for discharge on day 3 after the procedure.

\section{Discussion}

Midline laparotomy incision is often a straightforward procedure for treatment and resection of small bowel lesions. The long laparotomy wound, however, may cause a lot of pain, leading to prolonged hospital stay and more analgesic requirement that

\section{微創式腸鏡引導下進行小腸切除}

文俊軒、吳家駿、黃國華、莫碧添

為小腸病變部位準確定位一般很困難, 特別是肌壁間的小腸病變。即 使使用腹腔鏡, 要獲得病變清晰的影像並不容易。最準確的方法是以 剖腹直接探查和觸摸病變位置。然而最近的趨勢是利用微創手術把病 變安全及完整地切除, 同時減低手術創傷的機會。本文報告一宗以微 創式腸鏡引導下進行小腸切除的病例。

may impair respiratory function especially in patients with advanced age and multiple co-morbidities.

Although capsule endoscopy for identification of small bowel pathologies ${ }^{1,2}$ has become prevalent in patients with occult gastro-intestinal bleeding, sometimes it renders the operation difficult to accurately determine the site of lesion and locate the tumour.

The recent advances in surgical technology and development of new techniques have made minimally invasive procedures possible, like robotic surgery and endoscopic resection. However, the installation of these surgical instruments takes up a lot of space in the operating theatre and increases

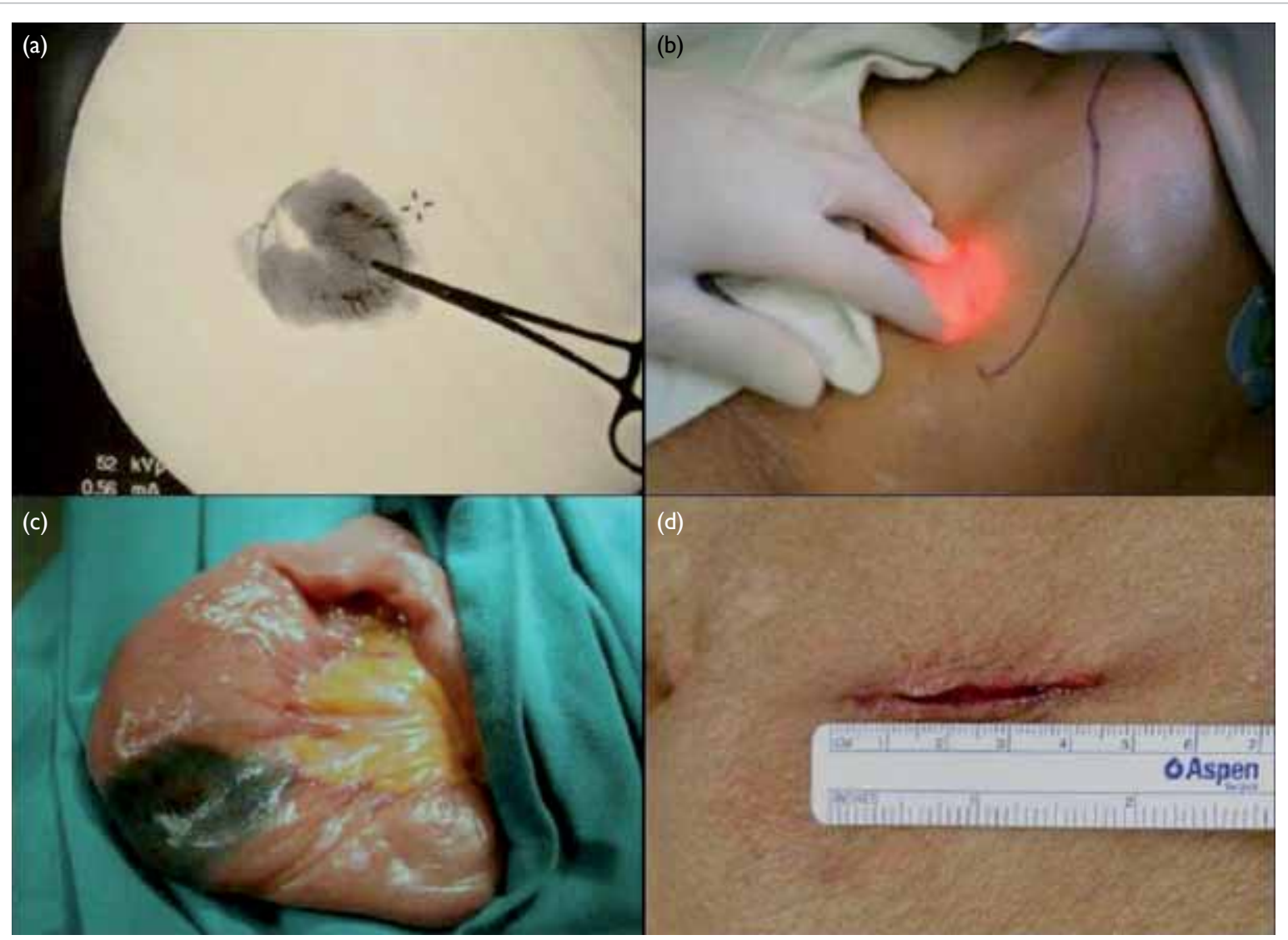

FIG 2. (a) Fluoroscopy scan and (b) transillumination of tumour. (c) Retrieval of small bowel and (d) length of incision 
the cost of enhancement, not to mention the huge maintenance cost. ${ }^{3,4}$ As such, we present a case of minimally invasive small bowel resection which is cost-effective to be adopted by most hospitals.

To recap, the aim of minimally invasive surgery is to reduce surgical morbidity with smaller and less wound while maintaining pathological clearance and safety. In our design, the use of enteroscope provided accurate localisation of the pathology by direct visualisation. ${ }^{5}$ After confirming the position of the pathology, the skin incision could be precisely made on top of the lesion. Before excising the lesion, laparoscopy was also performed to make sure that there was no intra-abdominal metastatic deposit. The wound was extended to $4.5 \mathrm{~cm}$ and this allowed the diseased small bowel to be retrieved for resection as in an open procedure (Fig 2d). The instruments used are readily available in most hospitals and the procedure can be performed at a relatively lower cost.

Single-balloon enteroscope, the procedure used in our case, is a recently developed technology for diagnosing small bowel pathology. The setup of this safe enteroscope is simple. ${ }^{6}$ Moreover, some evidence bore out that the learning curve of singleballoon enteroscope is insignificant. ${ }^{7,8}$ Previous study also showed that single-balloon enteroscope provided a diagnostic yield similar to double-balloon enteroscope which requires more technical skills. ${ }^{9}$

In this operation, three types of localisation methods were adopted after position of the tumour was confirmed by enteroscopy. These included lipiodol injection, transillumination to localise the incision site, and endomarker injection to find out precisely where the tumour was located.

Lipiodol injection at the site of tumour allows localisation of lesion under fluoroscopic guidance, which is useful to guide the site for skin incision. It can be done before operation, hence saves time during intra-operative enteroscopy. The exact position of the tumour, however, may not be easily located by laparoscope after identification of the incision site.

In such situations, injection of endomarker before operation is recommended during laparoscopy as this enables better visualisation of the portion of the diseased bowel to be retrieved for further resection. However, endomarker cannot replace lipiodol in localisation of lesion as it is not radio-opaque and cannot aid localisation of skin incision site.

Alternatively, transillumination using enteroscope allows real-time localisation of the incision site and this is superior to merely injecting lipiodol. However, the risk of complications arising from intra-operative enteroscope may be hiked up and the operating time may be extended.
To facilitate the operation and shorten the time required, preoperative enteroscopy rather than intra-operative enteroscopy should be employed. The injection of lipiodol and endomarker can be done before operation. As an initial attempt of our de-novo technique in this case, we decided to use intra-operative enteroscopy with transillumination for real-time tumour localisation even though the operating time was inevitably prolonged.

In addition to the above methods, the use of endoclip is considered a possible option for accurate localisation. Since endoclip is radio-opaque, it can serve both purposes for incision site and tumour localisation under fluoroscopic guidance. Nevertheless, the accuracy could be affected due to the risk of dislodgement of these endoclips.

\section{Conclusion}

Enteroscope is a safe option for guiding minimally invasive small bowel resection with accurate localisation of pathology. There are different ways for localisation including the use of endomarker, lipiodol injection, transillumination as well as endoclip. Large-scale studies using these techniques should be considered in order to understand the efficacy of such newer methods.

\section{References}

1. Mavrogenis G, Coumaros D, Bellocq JP, Leroy J. Detection of a polypoid lesion inside a Meckel's diverticulum using wireless capsule endoscopy. Endoscopy 2011;43 Suppl 2 UCTN:E115-6.

2. Mavrogenis G, Coumaros D, Lakhrib N, Renard C, Bellocq JP, Leroy J. Mixed cavernous hemangioma-lymphangioma of the jejunum: detection by wireless capsule endoscopy. Endoscopy 2011;43 Suppl 2 UCTN:E217-8.

3. Amodeo A, Linares Quevedo A, Joseph JV, Belgrano E, Patel HR. Robotic laparoscopic surgery: cost and training. Minerva Urol Nefrol 2009;61:121-8.

4. Kim CW, Baik SH. Robotic rectal surgery: what are the benefits? Minerva Chir 2013;68:457-69.

5. Ress AM, Benacci JC, Sarr MG. Efficacy of intraoperative enteroscopy in diagnosis and prevention of recurrent occult gastrointestinal bleeding. Am J Surg 1992;163:94-9.

6. Yoshiya S, Sugimachi K, Nakamura S, et al. Preoperative diagnostic value of single-balloon enteroscopy for successful surgical treatment of three independent-origin gastrointestinal malignant tumors: report of a case. Surg Today 2011;41:1007-10.

7. Upchurch BR, Sanaka MR, Lopez AR, Vargo JJ. The clinical utility of single-balloon enteroscopy: a singlecenter experience of 172 procedures. Gastrointest Endosc 2010;71:1218-23.

8. Tsujikawa T, Saitoh Y, Andoh A, et al. Novel single-balloon enteroscopy for diagnosis and treatment of the small intestine: preliminary experiences. Endoscopy 2008;40:11-5.

9. Domagk D, Mensink P, Aktas H, et al. Single- vs. doubleballoon enteroscopy in small-bowel diagnostics: a randomized multicenter trial. Endoscopy 2011;43:472-6. 